Revista Destaques Acadêmicos, Lajeado, v. 8, n. 4, 2016. ISSN 2176-3070

DOI: http://dx.doi.org/10.22410/issn.2176-3070.v8i4a2016.1230

www.univates.br/revistas

\title{
AS CONTRIBUIÇÕES DA EXTENSÃO PARA A FORMAÇÃO PESSOAL E PROFISSIONAL DE ACADÊMICOS BOLSISTAS DO PROJETO REDES INTERDISCIPLINARES
}

\author{
Aline Patrícia Hunemeier ${ }^{1}$, Adriana Belmonte Bergmann ${ }^{2}$, \\ Adriana Magedanz ${ }^{3}$, Andreia Spessatto De Maman ${ }^{4}$, Augusto Pretto Chemin 5 , \\ Hélder Conceição Pacheco ${ }^{6}$, Jane Herber ${ }^{7}$, Leonardo Roni Matte ${ }^{8}$, \\ Paloma Stacke ${ }^{9}$, Sônia Elisa Marchi Gonzatti ${ }^{10}$, Thomas dos Santos Muller ${ }^{11}$, \\ Werner Haetinger ${ }^{12}$
}

Resumo: Este trabalho visa apresentar algumas reflexões sobre as aprendizagens construídas na práxis da extensão universitária, considerando as percepções do grupo de bolsistas do projeto de Extensão Redes Interdisciplinares: Desvendando as Ciências Exatas e Tecnológicas. Para que se pudesse identificar as percepções e reflexões dos bolsistas o grupo de coordenadores elaborou um roteiro para a escrita de um texto coletivo por parte dos bolsistas a fim de se realizar uma análise qualitativa do conteúdo

1 Graduanda em Engenharia Civil. Bolsista de Extensão. Centro Universitário UNIVATES.

2 Licenciada em Ciências e Matemática. Mestre em Matemática Aplicada. Centro Universitário UNIVATES. Professora do CETEC.

3 Licenciada em Ciências e Matemática. Mestre em Ensino de Ciências Exatas. Centro Universitário UNIVATES. Professora do CETEC.

4 Licenciada em Ciências Exatas. Mestre em Ensino de Ciências Exatas. Centro Universitário UNIVATES. Professora do CETEC.

5 Graduando em Ciências Biológicas Licenciatura. Bolsista de Extensão. Centro Universitário UNIVATES.

6 Graduando em Química Industrial. Bolsista de Extensão. Centro Universitário UNIVATES.

7 Licenciada em Química. Mestre em Educação em Ciências Exatas. Centro Universitário UNIVATES. Professora do CETEC.

8 Graduando em Engenharia Mecânica. Bolsista de Extensão. Centro Universitário UNIVATES.

9 Graduanda em Engenharia Química. Bolsista de Extensão. Centro Universitário UNIVATES.

10 Licenciada em Ciências. Doutora em Educação. Centro Universitário UNIVATES. Professora do CETEC.

11 Graduando em Engenharia Mecânica. Bolsista de Extensão. Centro Universitário UNIVATES.

12 Licenciado em Física. Mestre em Computação. Centro Universitário UNIVATES. Professor do CETEC. 
apresentado. Integram o projeto professores colaboradores e bolsistas do Centro Universitário UNIVATES tendo como objetivo fomentar a educação nas diversas áreas do conhecimento, oferta diferentes oficinas de Matemática, Química, Física e Astronomia. Devido às oficinas serem desenvolvidas pelos bolsistas sob a supervisão dos orientadores, percebe-se a importância de investir na capacitação dos discentes do projeto. Essa formação foi iniciada com oficinas experimentais entre os integrantes, os quais compartilham conhecimentos e questionamentos. Além disso, tendo consciência da importância de aportes teóricos no embasamento da extensão universitária, foram realizadas leituras de referenciais relacionados a questões como interdisciplinaridade, divulgação científica e espaços não formais, os quais constituem a base teóricometodológica do projeto. Dessa forma, pode-se inferir que a extensão universitária não só permite agregar experiências e conhecimentos ao público externo, como também desenvolver habilidades e competências fundamentais no processo de formação pessoal e profissional dos bolsistas.

Palavras-chave: Formação. Extensão. Oficinas. Interdisciplinaridade. Divulgação científica.

\section{Introdução}

O projeto de extensão Redes Interdisciplinares: Desvendando as Ciências Exatas e Tecnológicas tem como objetivo fomentar a educação em Ciências Exatas, divulgando e difundindo o conhecimento científico e tecnológico junto à população do Vale do Taquari/RS e arredores, oportunizando a formação cidadã dos estudantes universitários. Formado por 13 professores colaboradores e 9 bolsistas de diversas áreas de estudo, abrange uma grande área do conhecimento - as Ciências Exatas -, oportunizando oficinas nas áreas da Matemática, Química, Física e Astronomia aos alunos da Educação Básica de diversas escolas da região do Vale do Taquari, assim como qualquer comunidade interessada nas atividades. Os bolsistas, sob orientação dos professores, são responsáveis pelo desenvolvimento das atividades a serem realizadas com os alunos. Uma delas ocorre no Planetário Móvel, bem adquirido com recursos externos em 2013. Nele são realizadas sessões com duração de aproximadamente 40 minutos, abordando histórias de constelações e simulando uma viagem espacial pelo sistema solar (FIGURA 1). 
Figura 1: vista interna do planetário

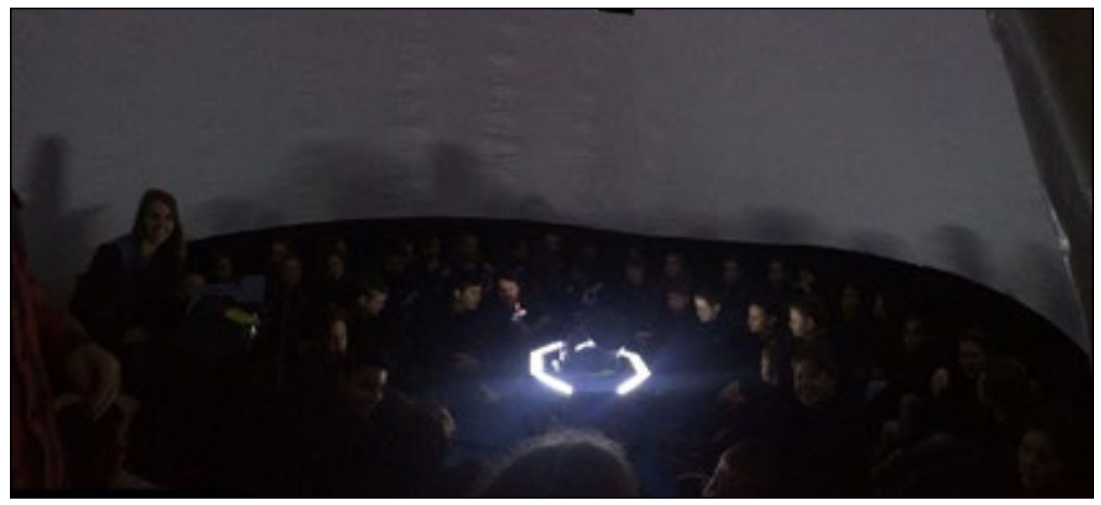

Fonte: Dos Autores

Outra oficina realizada pelos bolsistas é de Matemática e Física, a qual conta com o auxílio de aplicativos computacionais online tanto em tablets como em computadores. São criadas atividades que contemplem os conteúdos, visando a um aprendizado diferenciado aos alunos, pois acabam interagindo com as tecnologias. Na área da Química, são realizadas atividades nos laboratórios da Univates, por meio das quais os alunos colocam a teoria em prática, uma vez que a experimentação é a principal metodologia utilizada. No final da atividade, é entregue um questionário avaliativo, onde os participantes da oficina respondem a questões teóricas envolvendo aspectos conceituais sobre as práticas realizadas. Todos os materiais e reagentes utilizados são dos laboratórios da Instituição (FIGURA 2).

Figura 2: Oficinas experimentais de Química

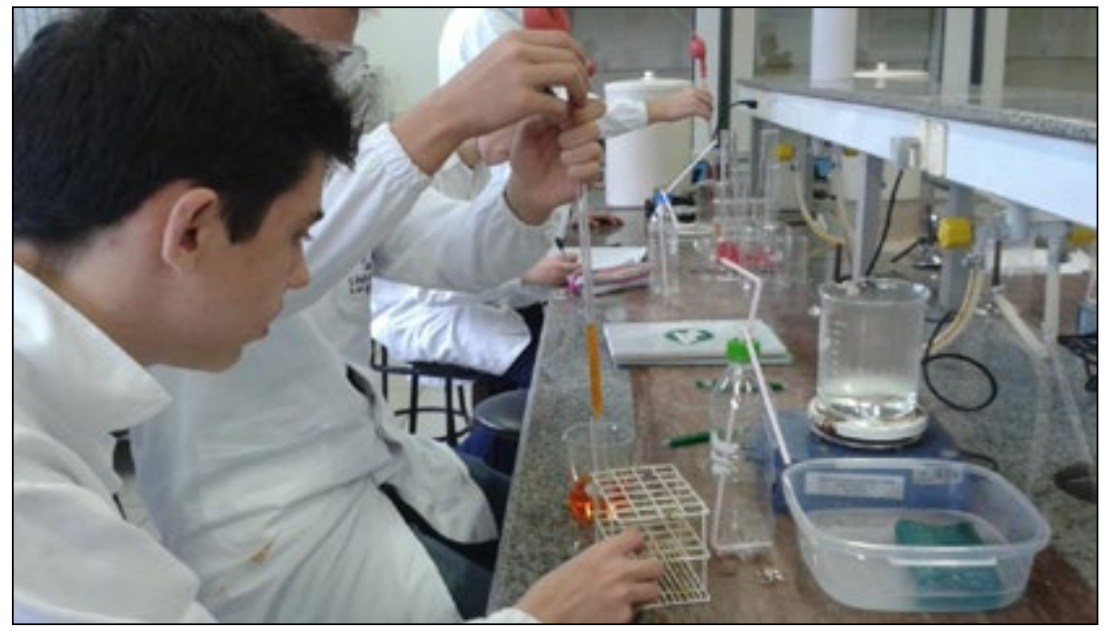

Fonte: Dos autores. 
O projeto ainda conta com uma oficina de Matemática, a qual é chamada de oficina da Olimpíada de Matemática da Univates, na qual os participantes resolvem questões de edições anteriores da Olimpíada com materiais concretos, podendo assim manuseá-los, não necessitando uma fórmula matemática para encontrar a solução do problema (FIGURA 3). Essa oficina incentiva o desenvolvimento do raciocínio lógico e da argumentação. Em todas as oficinas os alunos geralmente trabalham em grupos, com a mediação dos bolsistas e voluntários do projeto, desenvolvendo habilidades para trabalho em equipe.

Figura 3: Oficina de Matemática

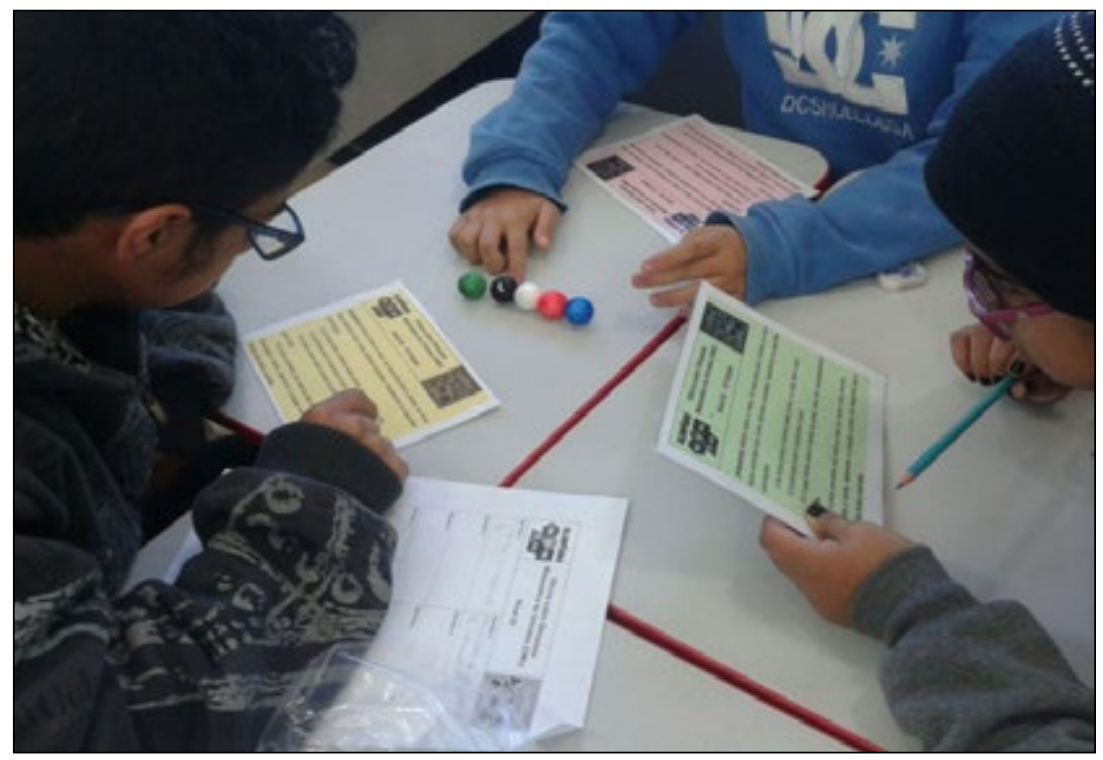

Fonte: Dos autores.

Na área da Astronomia, além do Planetário, o projeto possui oficinas experimentais e o observatório astronômico. O observatório está localizado no terraço do prédio 12 da Univates, e a observação do céu é feita com auxílio de um telescópio refletor. Antes da visualização direta com o telescópio, é explorado o software Stellarium, possibilitando uma melhor compreensão e a localização das estrelas mais brilhantes e facilmente. As oficinas experimentais abordam fenômenos do dia a dia, como dias e noites, estações do ano, fases da lua e eclipses; outro tema trabalhado é a história das principais constelações, explorando diferentes culturas. Em ambas as oficinas ocorrem interações com os participantes, que produzem os próprios materiais para as vivências realizadas. Em ambos os casos, são explorados os conhecimentos prévios dos participantes, por meio de questionários escritos ou questionamentos orais. Ainda sobre a oficina que envolve fenômenos astronômicos suas estratégias exploram a tridimensionalidade e a localização espacial. Segundo Leite e 
Housoume (2007), a exploração de modelos tridimensionais é fundamental para a compreensão adequada dos conceitos básicos da Astronomia, embora seja uma estratégia ainda pouco explorada no Ensino de Astronomia desenvolvido nas escolas. A Figura 4 mostra um grupo de alunos participando dessa vivência.

Figura 4: Modelo tridimensional para a compreensão das estações, translação terrestre e suas consequências

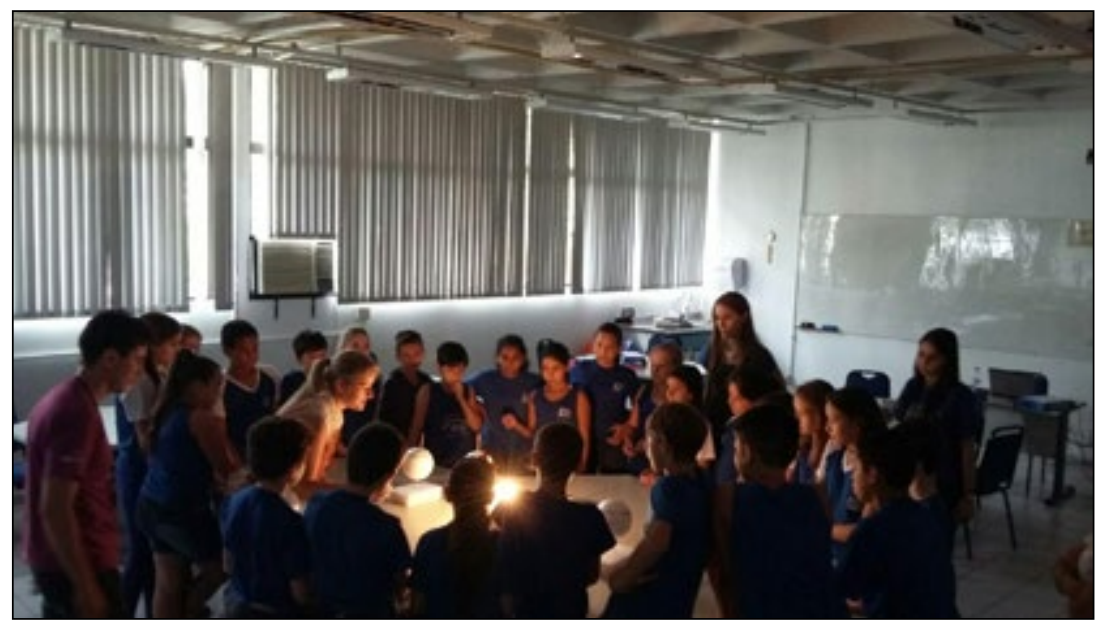

Fonte: Dos autores

$\mathrm{Na}$ oficina sobre as constelações, as crianças recebem uma folha que representa um pedacinho de céu,com vários pontos os quais simbolizam as estrelas. Por ser uma oficina realizada com crianças de até 10 anos, elas são instigadas a ligar os pontos, formando figuras, conforme seu interesse e criatividade. Depois que as figuras foram formadas os bolsistas mostram a arte de cada constelação no Stellarium. Geralmente, são trabalhadas as constelações de Órion (pela facilidade das pessoas em identificar as Três Marias), do Cruzeiro do Sul e do Escorpião. É explorada a ideia de que o nome e o desenho de cada constelação é fruto da criatividade de diferentes povos. Como exemplo das produções infantis, apresentamos a Figura 5, na qual também acrescentamos a arte original para efeito comparativo. 
Figura 5: Representações alternativas para a constelação de Órion

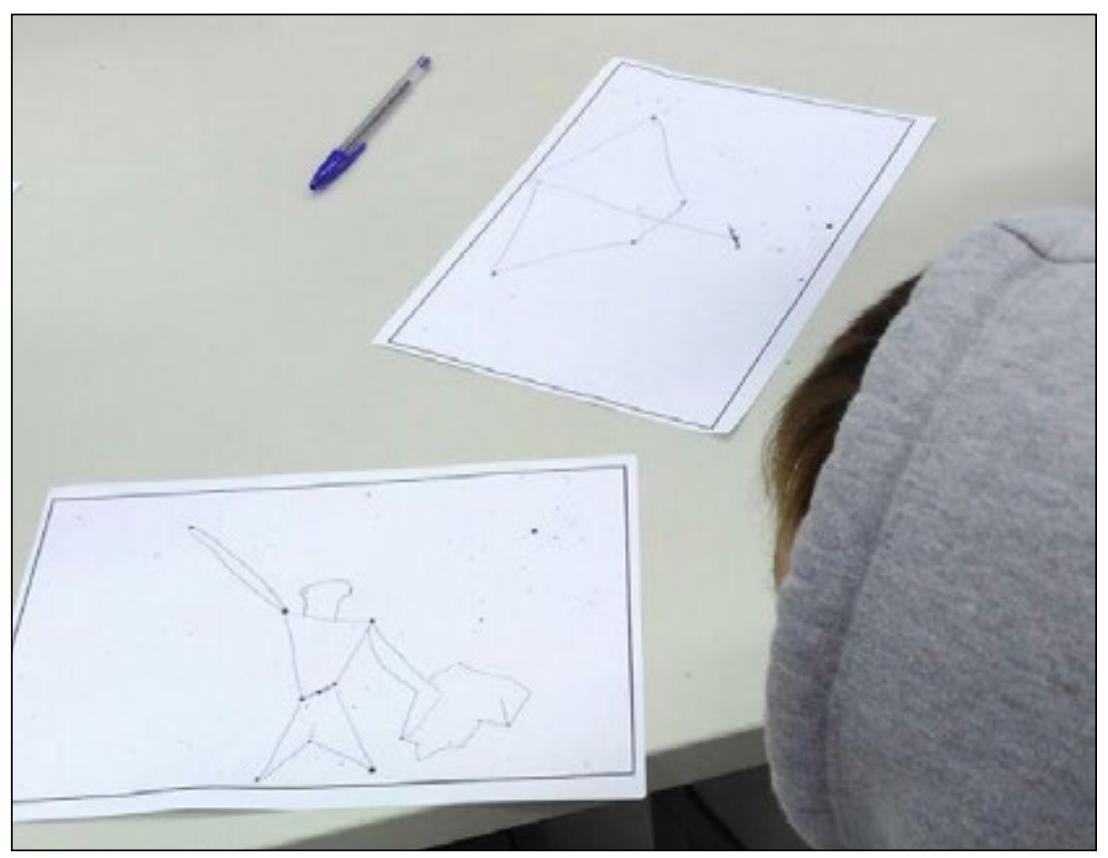

Fonte: Dos autores.

O projeto Redes Interdisciplinares foi concebido na perspectiva da alfabetização e da educação científica como direito dos cidadãos, destacando o potencial da educação não formal e da extensão universitária para a inclusão social e a aproximação destes do conhecimento científico e tecnológico. A ênfase do projeto está no desenvolvimento de ações que proporcionem a difusão da ciência e da tecnologia, estimulando o desencadeamento de processos de ensino e de aprendizagem dos temas básicos e contemporâneos das Ciências em uma perspectiva interdisciplinar e conectada com o uso de tecnologias como ferramenta aprendizagem e de inclusão social. Essa concepção está em consonância com as diretrizes da política de extensão da Univates e com as tendências da extensão universitária no contexto nacional, que passa a ser reconhecida como uma das dimensões estratégicas da atuação das universidades:

A extensão universitária, como um elemento inerente a esse projeto institucional, deve transformar-se numa possibilidade de aprendizagem, que, de acordo com as Diretrizes de Extensão (2009), constitui-se o eixo transversal para as atividades acadêmicas de ensino, de pesquisa e de extensão, que dá continuidade à articulação entre teoria e prática e que promove a integração entre universidade e sociedade, legitimando o projeto pedagógico da primeira, como geradora e sistematizadora de conhecimentos (SÍVERES, 2013, p.27). 
Ao entre cruzarmos a visão contemporânea da extensão e os objetivos e ações do projeto Redes, é possível inferir que a formação técnica, política e ética dos bolsistas e voluntários emerge como uma necessidade inerente à atuação dos mesmos na práxis da extensão. A articulação entre teoria e prática, a interação dialógica com diferentes comunidades, a contextualização e ressignificação dos saberes construídos na academia são princípios que devem pautar a formação dos agentes da extensão universitária. Portanto, o objetivo deste trabalho é refletir sobre as vivências dos bolsistas de extensão como oportunidade(s) de aprendizagem e de formação. Seguindo essa ideia central, serão apresentadas todas as atividades de formação que ocorrem no âmbito do projeto Redes Interdisciplinares. Na sequência, são elencados desafios e contribuições da extensão para a formação pessoal e profissional, segundo a percepção dos estudantes bolsistas que são coautores deste trabalho. O próprio exercício de pausa das atividades cotidianas para refletir e avaliar-se é processo fundamental na trajetória formativa de qualquer profissional. Por último, são apresentadas algumas considerações finais, a título de (in) conclusão, já que o processo de formação é permanente, contínuo e sistemático e o processo reflexivo não se encerra junto com esse texto. A essa reflexão, alia-se a necessidade de formação específica para bolsistas/monitores que atuam com divulgação científica, já que são agentes incumbidos de disseminar a cultura científica em grande escala, usando linguagem acessível e, ao mesmo tempo, mantendo o rigor científico. Nessa perspectiva teórica, nos pautamos nas reflexões dos trabalhos de Pavão e Leitão (2007), Barros, Boss e Dutra (2016) e Barros e Langhi (2016).

\section{Como ocorre a formação dos bolsistas no contexto do Redes}

Segundo Pavão e Leitão (2007), o papel de monitores em centros e museus de ciências é de fundamental importância, pois nestes lugares muitas vezes ocorre a utilização de botões prontos, onde os visitantes só precisam acionar um comando para que ocorra a explicação por meio de uma gravação. Mas este não é o método mais eficaz, pois muitos não permanecem no lugar até a explicação ser completa. No entanto, se esta explicação ocorrer por meio de um monitor, a probabilidade da experiência ser melhor compreendida é maior, pois estes buscam estimular os visitantes a interagirem uns com os outros e fazem com que eles tentem encontrar a solução do problema, não apenas entregando a resposta pronta. Desta forma, acabam estimulando a crítica, a curiosidade e a indagação dos visitantes. Ainda, os mesmos autores compartilham sua experiência do Espaço Ciência:

[...] O Espaço Ciência ratifica o seu compromisso com a formação de seus monitores, pois os identifica como os grandes responsáveis por transformarem o acesso ao conhecimento numa grande aventura, prazerosa, útil e transformadora. (PAVÃO e LEITÃO; 2007, p. 41) 
O mesmo ocorre neste Projeto de Extensão, onde há a utilização de materiais concretos e diferenciados nas oficinas realizadas e nas sessões do Planetário, pois de acordo com Pavão e Leitão (2007), não bastam cenários fantásticos e experimentos sofisticados. A interação dos monitores com os visitantes é muito importante, pois acaba fugindo do método diário de ensino utilizado pelos professores, e permite que a aprendizagem ocorra de uma forma mais proveitosa.

Nesse sentido, a formação de monitores é de extrema importância, pois desta forma possibilita a melhor compreensão dos monitores e auxilia na sua formação intelectual e no exercício pleno de seu papel como agentes de divulgação científica e formadores culturais.

Barros, Boss e Dutra (2016), responsáveis por realizarem formação de monitores no âmbito da Astronomia, afirmam que nesta área muitas vezes a formação ocorrida é mais técnica do que voltada para interação com o público e a aprendizagem. Isso se justifica, em parte, já que as atividades realizadas ocorrem por meio de planetário ou telescópio; sendo assim, para a utilização deste material, os monitores representados por bolsistas ou voluntários necessitam um maior conhecimento da funcionalidade dos equipamentos. Ainda na visão desses autores, alguns monitores relatam dificuldades em trabalhar com oficinas em forma de palestras, pois possuem receio de serem mal compreendidos, e sentem falta de conhecimentos prévios nas áreas de Astronomia e Física. Na pesquisa feita pelos autores supracitados, apenas alguns monitores responderam que não sentem dificuldades nas oficinas oferecidas pelo projeto. Os autores acreditam que estes monitores são representados pelos veteranos, que já realizaram todas as oficinas mais vezes. Como é possível perceber, a rotatividade de bolsistas é um desafio geral no contexto do trabalho com extensão universitária.

No que se refere ao Projeto Redes inicialmente será apresentado o perfil dos bolsistas que já participaram ou participam da equipe de trabalho do projeto. Os bolsistas são jovens com idade entre 19 e 25 anos. Quanto aos cursos de origem, já participaram graduandos de variados cursos, como: Administração de empresas, Licenciatura em Ciências Exatas, Arquitetura e Urbanismo. Atualmente, os integrantes do projeto são oriundos dos cursos de Engenharia Civil, Engenharia Mecânica, Química industrial, Engenharia Química e Licenciatura em Ciências Biológicas. Os mesmos têm em média 5 semestres já cursados, variando de 3 semestres cursados até 8 semestres. Como é perceptível, a maioria dos bolsistas não possuem seus cursos ligados à docência, como ocorre com os cursos de licenciatura, havendo assim uma necessidade de preparação para trabalhar com o público em geral, principalmente quando se trata de crianças.

A seguir, serão apresentadas as diferentes ações de formação que são desenvolvidas no âmbito do projeto, visando a qualificar a atuação dos bolsistas e voluntários como agentes de divulgação científica e da práxis extensionista. 


\subsection{Formações sobre as diferentes oficinas do Redes}

No mês de março de 2016, foram organizadas atividades na forma de aulas experimentais e teóricas pelos professores colaboradores e também por bolsistas mais experientes, com o intuito de melhorar a compreensão dos participantes do projeto acerca dos fenômenos e conceitos que viriam a ser abordados futuramente nas atividades que seriam desenvolvidas. As mesmas têm ênfase na realização de experimentos simples, focando a interação por parte dos estudantes da Educação Básica, que são o público alvo das oficinas que viriam a ser desenvolvidas.

No que se refere as oficinas de Astronomia, enfatizam-se os aspectos observacionais e os conhecimentos espaciais. Trabalha-se com a tridimensionalidade representando o planeta Terra por uma bola de isopor e o Sol por uma lâmpada ${ }^{13}$; desta forma é possível representar a dinâmica do sistema Sol-Terra, a ocorrência do dia e da noite, das estações do ano, entre outros fenômenos. A formação para as oficinas de Astronomia se fez tanto no aspecto prático com a participação em oficinas como com aporte teórico, sendo as leituras abrangentes para o desenvolvimento tanto no conhecimento do posicionamento, dinâmica e formas dos astros, como também uma aprendizagem didática de como melhor transmitir este conhecimento.

Foram realizadas sessões de observações do céu noturno e pesquisas sobre o funcionamento de telescópios, para a operação do telescópio da instituição, bem como para o desenvolvimento das oficinas de observação onde bolsistas e professores operam o equipamento, proporcionando aos visitantes e estudantes a observação de planetas, estrelas e outros objetos celestes.

Para a operação do planetário foram desenvolvidas dinâmicas para que os bolsistas conhecessem o funcionamento dos sistemas de projeção, dinâmica entre áudios e movimentação das estrelas e projeção de astros. Foram realizadas diversas montagens e desmontagens, juntamente com a criação de um passo a passo para facilitar o trabalho, assim como instruções de como agir em situações incomuns como, por exemplo, desmaios, mal-estar, falta de energia elétrica e como atuar para regrar o comportamento infanto-juvenil durante as sessões.

Nas oficinas de Ciências, que envolvem conceitos de Química, Física e Matemática, há preferência por realizar experimentos que evidenciam conteúdos já trabalhados em sala de aula, possibilitando que o estudante da graduação dê novos significados e potencialize os conhecimentos como magnetismo, física térmica, separação de misturas, entre outros que aproximam conceitos de Física e Química. Por não haver limitação quanto a idade para participar das oficinas propostas, necessita-se flexibilizar a linguagem e a dinâmica no desenvolvimento das atividades por parte dos bolsistas. Também

13 Neste caso, os participantes são alertados de que não há proporção no que tange aos tamanhos reais do Sol e da Terra. 
cabe destacar que os bolsistas, ao organizarem e planejarem as oficinas utilizam conhecimentos vistos na graduação e são desafiados a buscarem complementações para o êxito na realização das mesmas.

A preparação para a oficina "Olimpíada Matemática da Univates" ocorreu por meio de leituras sobre o histórico da Olimpiada, rodas de conversa a respeito do assunto, ministrada por bolsistas mais antigos e professores envolvidos nas edições anteriores, como também por meio de pesquisas em banco de questões de outras olimpíadas de matemática que ocorrem em âmbito nacional. Além da preparação teórica, foram elaboradas questões e materiais para a resolução das mesmas, usando da criatividade para desenvolver e adaptar métodos de resolução diferenciados.

Desde o início do projeto até o presente momento as oficinas recebem constantes atualizações com intuito de qualificar, tanto a didática dos bolsistas para com os alunos, como o aperfeiçoamento dos conhecimentos de conteúdos associados às atividades do projeto. Juntamente com esta iniciativa sempre é disponibilizado um espaço frequente para perguntas e sugestões, visto que a função principal das oficinas é incentivar os alunos a criarem laços e estabelecerem conexões com a ciência a fim de melhorar a qualidade da aprendizagem.

Para a realização das oficinas de aplicativos computacionais os bolsistas participaram de atividades semelhantes àquelas que eles viriam a ministrar aos alunos da Educação Básica em futuros atendimentos. A preparação foi conduzida por bolsistas mais antigos e professores especialistas na área, em laboratório de informática, e outras com a utilização de tablets, assim dominando a utilização dos softwares como ferramenta de aprendizagem.

\subsection{Formações sobre os referenciais teóricos do projeto}

Além das formações que os bolsistas tiveram no início do projeto sobre as oficinas, ainda são realizadas frequentemente formações sobre referenciais teóricos pertinentes ao projeto Redes. Já ocorreram três destas formações, sendo elas ministradas tanto pelos professores como pelos bolsistas, para possibilitar desta forma um maior conhecimento na área da interdisciplinaridade, da educação não formal e da alfabetização científica, que são as principais bases das ações do projeto.

A primeira formação que ocorreu foi no mês de agosto, quando um dos bolsistas ficou responsável por realizar uma apresentação sobre o tema interdisciplinaridade. O bolsista em questão apresentou para os demais bolsistas e professores do projeto a partir de dois artigos pré-selecionados pelos professores (KETZER; 2007; THIESEN; 2008). Neste momento, também uma docente apresentou sobre o mesmo tema, mas abordando conceitos de multidisciplinaridade, interdisciplinaridade e transdisciplinaridade, de acordo 
com Japiassu (1976). E após as apresentações ocorreu um debate sobre os temas abordados com todo o grupo participante.

A segunda rodada de formações ocorreu em setembro e foi ministrada pelas professoras do projeto, que dispuseram de materiais físicos para auxiliar os bolsistas. Estes deveriam utilizar o material para demonstrar visualmente os significados e conceitos que a interdisciplinaridade aborda. $\mathrm{O}$ desafio consistiu em explicitar redes de conceitos que eles percebem que podem representar aproximações entre diferentes conceitos científicos que são trabalhados nas oficinas. A proposta teve como objetivo aproximar teoria e empiria, evidenciando níveis de interdisciplinaridade que são construídos na práxis do projeto Redes. O material criado para a representação foi uma teia interligando diversas áreas, não apenas as Ciências Exatas.

Durante a formação realizada no mês de outubro, ocorreu uma apresentação organizada por três bolsistas do projeto para o grupo de professores e demais bolsistas. Neste dia foram abordados conceitos de alfabetização científica, divulgação científica, espaços formais, não formais e informais, segundo autores que sustentam a concepção teórico-metodológica do projeto.

Estas formações ocorrem sempre alterando o responsável pela apresentação, para possibilitar que todos compreendam os assuntos e consequentemente se qualifiquem gradativamente. Atualmente, os bolsistas estão estudando referenciais e trabalhos de pesquisa já publicados que envolvem a práxis da extensão como espaço de formação e de aprendizagem, enfocando o viés da formação de monitores/bolsistas para atuar na divulgação científica. É necessário salientar que o projeto Redes absorveu diferentes atividades que ocorriam no âmbito de projetos voltados à Astronomia, que se caracterizam fortemente pelo compromisso com a divulgação científica e popularização da ciência.

\subsection{A formação em "ação"}

O projeto oportuniza aos bolsistas vivências em diferentes instituições de ensino da região e experiências em diversas áreas do conhecimento, mostrando a grande variedade de entendimentos necessários aos ministrantes de oficinas, ressaltando a necessidade e importância de desenvolver habilidades ligadas à postura e diálogo em público.

Ser bolsista de extensão é a oportunidade de um estudante graduando de nível superior vivenciar atividades muitas vezes restritas à docência. Em outras palavras, discentes que atuam na extensão universitária têm espaço para experimentar as funções ligadas ao ensino, na ótica do professor. O bolsista, sendo responsável por planejar, desenvolver e conduzir as oficinas se vê no papel oposto ao usual no processo de ensino. Desta forma, com o passar do tempo e perfil das oficinas, algumas táticas didáticas são aprendidas de acordo 
com a faixa etária e série dos estudantes. Por exemplo, nos anos iniciais tem-se maior dificuldade de explicar aos alunos conceitos científicos mais complexos, tornando necessária a habilidade de simplificar explicações, utilizar exemplos do seu cotidiano e saber ouvi-los também, pois os "pequenos" gostam bastante de compartilhar experiências, por mais simples que elas sejam. Nos anos finais, a partir do $6^{\circ}$ ano, os alunos são mais suscetíveis a explicações científicas, mas também é possível notar uma certa timidez na maioria dos estudantes, e é um padrão que frequentemente se repete, tornando necessária uma abordagem ainda informal, se comparada com a sala de aula, para que eles se sintam seguros para participar. No ensino médio, muitos estudantes demonstram uma ótica diferenciada das atividades, pois eles se veem próximos ao possível ingresso em uma instituição de ensino superior, dando mais importância à oficina e se identificando, fazendo perguntas sobre a área trabalhada.

Portanto, podemos afirmar que a prática é um espaço privilegiado de formação. Temos que lidar com imprevistos, com situações reais, com diferentes perfis de escola e de alunos, faixas etárias. Estar ali, coordenando e mediando situações de aprendizagem, é oportunidade ímpar de aprendizagem. $\mathrm{Na}$ rotina do projeto, conversa frequentemente sobre aspectos que podem ser melhorados, avaliando toda a dinâmica envolvida no desenvolvimento de uma ação com diferentes perfis dos participantes.

Também a escrita acadêmica da qual os bolsistas participam, em vários momentos, é uma oportunidade importante de aprendizagem e de qualificação como estudantes universitários. No caso do salão de extensão, cada bolsista produziu seu texto, em várias versões, com a orientação de um docente. Escritas coletivas são orientadas por docentes responsáveis, a partir de um sumário de ideias a ser desenvolvido, e o texto é produzido de maneira compartilhada no google Docs.

\subsection{Orientações individuais com os professores da equipe}

Desde o início do projeto, os bolsistas são aconselhados e observados por docentes orientadores, que são responsáveis pela orientação de mais de um bolsista. Cada bolsista possui um docente orientador, todavia isto não limita a ação do grupo docente, pois comumente ocorrem relações de orientações e distribuição de atividades por docentes que não sejam necessariamente orientadores, assim proporcionando uma flexibilidade quanto às relações interpessoais. Tal articulação também se justifica pela intensa integração que ocorre na equipe de trabalho do projeto. A dinâmica de trabalho e de organização é conhecida e discutida por todos. Também ocorre rodízio dos bolsistas responsáveis tanto pela organização prévia das ações quanto por mediar e conduzir as oficinas.

O papel dos orientadores não se resume a servir com o ofício de autoridade para distribuir atividades, possuindo importância na orientação do 
crescimento pessoal e profissional, indicando o caminho, porém permitindo que o orientado dê seus próprios passos. A atenção disponibilizada à formação de cada um não fica em função de uma única figura, pois como o projeto possui docentes com diversas formações, estes passam seus conhecimentos para o grupo de bolsistas visando uma formação mais completa para todos.

\section{Reflexões: aprendizagens e contribuições para formação pessoal e profissional}

O objetivo dessa seção é evidenciar as reflexões, a partir das percepções compartilhadas pelos bolsistas por meio de um documento disponibilizado para toda equipe no Google Drive, onde cada um escreveu sobre suas atividades realizadas fazendo uma breve reflexão sobre as mesmas além de inserir aportes teóricos embasados pelo projeto de extensão em questão. Realizando uma análise qualitativa sobre o relato de cada bolsista é possível apontar as contribuições das práticas extensionista para a formação integral do estudante universitário. Para Flick (2009) a pesquisa qualitativa não está baseada em um único conceito teórico e metodológico. Para o autor a pesquisa qualitativa está ligada a análise de dados concretos em suas particularidades locais e temporais, partindo das expressões e atividades das pessoas em seus contextos locais (FLICK, 2009, p.37). Sendo assim, a pesquisa realizada com os bolsistas está embasada na análise qualitativa, pois possui uma variedade de abordagens bem como vem sendo identificada como relevante nas pesquisas contemporâneas em muitas áreas.

Esta abordagem está concatenada à concepção da extensão como um princípio de aprendizagem (SÍVERES, 2008, 2013) e a um novo status quo que a extensão vem conquistando dentro da dinâmica da atuação das universidades no Brasil. Sobre esse aspecto, é necessário salientar que a Univates têm tido uma atuação muito propositiva e coerente com as diretrizes da Política Nacional de Extensão, pautando sua política em princípios como a relação dialógica com a comunidade, a indissociabilidade ensino-extensão-pesquisa, a simbiose de saberes e a interdisciplinaridade (PDI/UNIVATES, 2017/2021, 2015). Nessa perspectiva, é possível evocar o potencial da extensão para tencionar as práticas de ensino tradicionais no Ensino Superior, avançando na direção da formação conectada com os problemas concretos do (futuro) contexto da atuação profissional dos estudantes de graduação:

A universidade tem como função a formação de pessoas com o intuito de atender às necessidades da comunidade. Assim, o estudante deveria já durante o curso de graduação, ter a possibilidade de atuar com dinamismo, colocando em prática o que está aprendendo. Acredita-se que isso pode ser proporcionado pelas atividades de extensão, as quais oferecem um preparo que talvez não seja possível somente com as disciplinas tradicionais de um curso. No entanto, não se pode esquecer a formação humana, em que é destacado o 
aprendizado da vida, da cidadania, das relações entre profissionais e usuários (GONZATTI, DULLIUS, QUARTIERI, 2013, p. 231).

$\mathrm{Na}$ sequência, são apresentados os aprendizados dos bolsistas relacionados com as interações com a comunidade, tendo em vista a variedade de oficinas desenvolvidas e as realidades locais.

\subsection{O que se aprende na interação com as comunidades?}

A interação com a comunidade traz diversos pontos positivos para o desenvolvimento pessoal e profissional dos bolsistas, como a melhor desenvoltura na fala, as relações interpessoais, a capacidade de compartilhar conhecimentos já adquiridos. Diante das interações com a comunidade, percebese o envolvimento e desenvolvimento dos bolsistas a cada atividade realizada. Apesar de haver uma grande diversidade de termos, o que está em pauta é a possibilidade de se criarem espaços de interação e de trabalho entre as pessoas para ampliação dos conhecimentos. A cada Mostra Científica Itinerante ${ }^{14}$ (MCI) realizada, os bolsistas devem agir de forma diferente, dependendo da série e idade, e o conhecimento deve se estender desde o ensino fundamental até o médio, a interação com o público deve ser de forma clara, objetiva e de fácil entendimento.

As diferentes realidades conhecidas durante as atividades do projeto, principalmente as MCI, ampliam a percepção sobre o mundo, pois há contato tanto com realidades de ensino de alto nível e padrão de vida, tanto com realidades com deficiências, tanto financeiras como educacionais, não raramente andando lado a lado. A compreensão destas realidades faz com que os integrantes do projeto tenham uma melhor visão da realidade, assim ajudando-os a se desenvolverem não apenas como estudantes e profissionais, mas principalmente como pessoa, desenvolvendo valores como solidariedade, respeito ao outro e às diferenças, alteridade, resiliência, entre outros.

\subsection{Como trabalhar na extensão contribui para a formação pessoal e profissional?}

Para os bolsistas em geral, com as constantes oficinas realizadas, vivenciam novas experiências; entre elas está o desenvolvimento da comunicação com os alunos de diversas idades, tendo em vista a necessidade de uma linguagem de fácil entendimento entre eles, requintado as explicações dadas aos mesmos, como também as atitudes tomadas em sala de aula. Aprende-se também a trabalhar em grupo, tendo que confeccionar material, separar as atividades, reservar laboratório, realizar a escrita de artigos

14 Atividade do projeto como oficinas e planetário que são realizada em instituições de ensino. 
acadêmicos, tudo sendo praticado em um grupo de nove bolsistas de extensão (cenário de dez/2016).

Para os bolsistas da área da licenciatura, ter a experiência de realizar uma oficina com alunos da Educação Básica é uma preparação para o futuro. Percebe-se as facilidades e dificuldades de preparar uma aula que motive e chame a atenção dos alunos, que seja construtiva, prática e com caráter interdisciplinar, juntando várias disciplinas na explicação de um assunto. Os bolsistas de bacharelado também adquirem diversos conhecimentos e a cada dia este vai sendo intensificado. A desenvoltura para falar em público e o conhecimento sobre a matéria a ser ministrada tanto nas Mostras Científicas Itinerantes quanto nas oficinas, são aspectos que cada bolsista vai levar para a formação pessoal, enaltecendo cada vez mais sua desenvoltura. Ainda, trabalhar com a interdisciplinaridade possibilita perceber o quanto os problemas concretos e reais com os quais se pode vir a lidar no exercício profissional exigem conexões entre diferentes áreas e não são delimitados por limites estanques como pressupõe o modelo de ensino baseado no código disciplinar e nos pressupostos da ciência positivista.

Não reduzindo essa reflexão apenas às experiências em sala de aula e as ligadas às Ciências Exatas, há um aprendizado na questão da gestão do projeto, onde se tem contato com controle de gastos, organização de materiais, logística, arquivamento e escrita acadêmica, organização e sistematização de dados e geração de estatísticas, oportunizando preparação teórico-prática sobre funcionamento e gestão de uma equipe para a eficiência das atividades desenvolvidas. Tem-se a oportunidade de vivenciar uma infinidade de fatores não aprendidos em sala de aula que estão diariamente presentes no trabalho com a extensão, sendo estes muito variados devido a gama de atividades realizadas pelos integrantes.

Por trabalhar com diferentes áreas das Ciências, o projeto de Extensão possibilita que os bolsistas compreendam assuntos importantes relacionados ao dia a dia, que aprendam a utilizar a interdisciplinaridade como ferramenta indispensável, tanto no projeto quanto para a vida pessoal e profissional, pois conseguindo interligar diversas áreas, possibilita ter uma visão geral das coisas, sendo possível encontrar a solução para problemas de forma mais simples, do que tendo a visão apenas de uma pequena parte do problema, possibilita adquirir experiência profissional e fazer a ligação dos conteúdos teóricos com a prática.

\subsection{Habilidades para ser bolsista da extensão deste projeto}

Para ser bolsista de extensão do projeto Redes são necessárias algumas habilidades como pró-atividade, saber trabalhar em grupo e realizar as atividades propostas pelas coordenadoras do projeto; boa desenvoltura para lidar com crianças. Um bom comportamento é essencial durante as oficinas, pois 
os alunos veem os bolsistas como exemplo. Em hipótese alguma os conteúdos deverão ser passados de uma maneira equivocada aos alunos; entendimento principalmente em áreas como Matemática, Astronomia, Física e Química.

Ao longo do ano de 2016, foram realizadas várias oficinas, nas quais demandaram uma elevada concentração dos bolsistas na confecção e organizações dos materiais didáticos, transporte de materiais, cuidados com os equipamentos. Organização e responsabilidade são indispensáveis durante a carreira de um bolsista do Centro Universitário UNIVATES. Assim, a busca de conhecimento é uma habilidade que o bolsista deve desenvolver no dia a dia.

\section{Considerações Finais}

Durante o processo de formação dos bolsistas, foram ministradas oficinas para os mesmos, onde se abordou informações importantes referentes aos materiais utilizados. A maneira correta de se portar em frente aos estudantes de uma Instituição de ensino, organização dos materiais, montagem e manejo dos aparatos do planetário, comportamento em um laboratório de ciências e laboratório de informática. Tudo isso representou um grande desafio para todos os bolsistas, pois tiveram apenas um mês para se apropriar dos conhecimentos e das atividades que seriam desenvolvidas antes de iniciar as atividades com público externo. O desenvolvimento de artigos acadêmicos também gerou dificuldades, pois exigiram um vocabulário amplo de cada um dos envolvidos, junto com leituras de vários artigos de autores conhecidos na área de ensino de ciências, educação não formal, interdisciplinaridade, entre outros.

Contudo, o primeiro ano do projeto de extensão Redes Interdisciplinares: Desvendando as Ciências Exatas e Tecnológicas, foi de grandes conquistas; todas as metas estabelecidas pelo projeto Redes Interdisciplinares foram superadas em grandes números. Diversos avanços em relação às oficinas ministradas, novos conhecimentos adquiridos, novos trabalhos realizados, dentre eles a participação em eventos externos, no Salão de Extensão da Univates, artigos acadêmicos publicados e diversas Mostras Científicas Itinerantes bem sucedidas são alguns fatores que demonstram o amplo espectro de aprendizagens conceituais, relacionais, técnicas, procedimentais e atitudinais que nos foram oportunizadas pela experiência como bolsistas de extensão, de certa forma transgredindo fronteiras disciplinares e avançando na percepção de que o conhecimento é dinâmico, complexo e sistêmico.

\section{Referências}

BARROS, L. G; BOSS, S. L. B.; DUTRA, G. Uma avaliação da formação de monitores em um projeto de divulgação da Astronomia. In: Atas do XVI Encontro de Pesquisa em Ensino de Física. Natal, 2016. 
BARROS, L. G.; LANGHI, R. Formação de monitores para atividades de divulgação e popularização da Astronomia: Uma necessidade atual. IV Simpósio Nacional de Educação em Astronomia - IV SNEA. Goiânia, 2016. Disponível em: http:/ / www.sabastro.org.br/resources/Documents/snea4/Caderno Resumos-IVSNEA.pdf. Acesso em novembro/2016.

FLICK, U. Introdução a pesquisa qualitativa. Porto Alegre - Artmed, p. 238-253, 2009.

GONZATTI, S.E.M.; DULLIUS, M.M.; QUARTIERI, M. T. O potencial da extensão para a formação profissional. p.223-244. In: A Extensão universitária como um princípio de aprendizagem. Brasília: Liber Livros, 2013.

JAPIASSU, H. Interdisciplinaridade e patologia do saber. Rio de Janeiro: Imago Editora, 1976, 221p.

KETZER, S.M. Ensinar e aprender no jogo da interdisciplinaridade. In: AUDI, Jorge Luís Nicolas; Morosini, Marilia Costa. Inovação e interdisciplinaridade na Universidade. Porto Alegre: EDIPUCRS, 2007, p. 91-100.

LEITE, C.; HOSOUME, Y. Os professores de Ciências e suas formas de pensar a Astronomia. Revista Latinoamericana de Educação em Astronomia - RELEA, n.4, p. 47-68, 2007. Disponível em: http:/ / web-02.ufscar.br/relea/index.php/relea/article/ view/99. Acesso em novembro/2016.

PAVÃO, A. C.; LEITÃO, A. Hands-on? Minds-on? Hearts-on? Social-on? Explainers on! In: MASSARANI, L. (Org.). Diálogos \& Ciência: mediação em museus e centros de ciência. Rio de Janeiro: Museu da Vida / Casa de Oswaldo Cruz / Fiocruz, p. 4046, 2007.

POLÍTICA DE EXTENSÃO INSTITUCIONAL, 2015, In: Plano de Desenvolvimento Institucional 2017-2021, p. 99-115 (documento interno). Disponível em: http:/ /www. univates.br/virtual/pluginfile.php $/ 717587 / \mathrm{mod} \_$resource/content $/ 1 /$ Proposta $\% 20$ PDI\%202017-2021\%20Universidade.pdf. Acesso em agosto/2016.

SÍVERES, L. O princípio da aprendizagem na extensão universitária. In: A Extensão universitária como um princípio de aprendizagem. Brasília: Liber Livros, p. 19-33, 2013.

SÍVERES, L. A extensão como um princípio de aprendizagem. Revista Diálogos: Universidade do Século XXI: a contribuição da extensão na busca da aprendizagem. Brasília, vol. 10, p. 8-17, 2008. Disponível em: https://portalrevistas.ucb.br/index. $\mathrm{php} / \mathrm{RDL} /$ article/view/1946. Acesso em novembro/2016.

THIESEN, J.S. A interdisciplinaridade como um movimento articulador no processo ensino-aprendizagem. In: Revista Brasileira de Educação, v. 13, n. 39, set/dez 2008. p. 546-554. 